\title{
HCV-infected individuals have higher prevalence of comorbidity and multimorbidity: a retrospective cohort study
}

Curtis L. Cooper ${ }^{1,2,8^{*}}$ D, Chrissi Galanakis², Jessy Donelle ${ }^{3}$, Jeff Kwong ${ }^{3,4,5}$, Rob Boyd ${ }^{6}$, Lisa Boucher ${ }^{7}$ and Claire E. Kendall $2,3,7,8,9$

\begin{abstract}
Background: Almost 1\% of Canadians are hepatitis C (HCV)-infected. The liver-specific complications of HCV are established but the extra-hepatic comorbidity, multimorbidity, and its relationship with HCV treatment, is less well known. We describe the morbidity burden for people with HCV and the relationship between multimorbidity and HCV treatment uptake and cure in the pre- and post-direct acting antiviral (DAA) era.

Methods: We linked adults with HCV at The Ottawa Hospital Viral Hepatitis Program as of April 1, 2017 to provincial health administrative data and matched on age and sex to 5 Ottawa-area residents for comparison. We used validated algorithms to identify the prevalence of mental and physical health comorbidities, as well as multimorbidity (2+ comorbidities). We calculated direct age- and sex-standardized rates of comorbidity and comparisons were made by interferon-based and interferon-free, DAA HCV treatments.

Results: The mean age of the study population was 54.5 years (SD 11.4), 65\% were male. Among those with HCV, 4\% were HIV co-infected, 26\% had liver cirrhosis, 47\% received DAA treatment, and 57\% were cured of $\mathrm{HCV}$. After accounting for age and sex differences, the HCV group had greater multimorbidity (prevalence ratio (PR) 1.38, 95\% confidence interval (CI) 1.20 to 1.58) and physical-mental health multimorbidity (PR 2.71, 95\% Cl 2.29-3.20) compared to the general population. Specifically, prevalence ratios for people with HCV were significantly higher for diabetes, renal failure, cancer, asthma, chronic obstructive pulmonary disease, substance use disorder, mood and anxiety disorders and liver failure. HCV treatment and cure were not associated with multimorbidity, but treatment prevalence was significantly lower among middle-aged individuals with substance use disorders despite no differences in prevalence of cure among those treated.

Conclusion: People with HCV have a higher prevalence of comorbidity and multimorbidity compared to the general population. While HCV treatment was not associated with multimorbidity, people with substance use disorder were less likely to be treated. Our results point to the need for integrated, comprehensive models of care delivery for people with HCV.
\end{abstract}

Keywords: HCV, Comorbidity, Multimorbidity, Direct acting antiviral

\footnotetext{
* Correspondence: ccooper@toh.ca

'Department of Medicine, University of Ottawa, Ottawa, Canada

${ }^{2}$ Clinical Epidemiology Program, Ottawa Hospital Research Institute, The

Ottawa Hospital-General Campus, G12-501 Smyth Rd, Ottawa, Ontario

K1H8L6, Canada

Full list of author information is available at the end of the article
}

(c) The Author(s). 2019 Open Access This article is distributed under the terms of the Creative Commons Attribution 4.0 International License (http://creativecommons.org/licenses/by/4.0/), which permits unrestricted use, distribution, and reproduction in any medium, provided you give appropriate credit to the original author(s) and the source, provide a link to the Creative Commons license, and indicate if changes were made. The Creative Commons Public Domain Dedication waiver (http://creativecommons.org/publicdomain/zero/1.0/) applies to the data made available in this article, unless otherwise stated. 


\section{Background}

Approximately $1 \%$ of Canadians are hepatitis C (HCV)infected [1, 2]. Among a wide range of infectious diseases, HCV confers a greater burden with respect to premature mortality and reduced functioning [3]. The liver-specific complications of $\mathrm{HCV}$, including liver failure and hepatocellular carcinoma, are well established, as are the benefits of curative $\mathrm{HCV}$ antiviral therapy on these outcomes [4]. In contrast, the burden of associated extra-hepatic comorbidity is less well known. Several studies have established the association of HCV with chronic kidney disease and renal impairment [5-10], depression [11-13], neurological disorders [14] and malignancies $[15,16]$, whereas the evidence is less consistent for association with diabetes mellitus [7, 17-19] and cardiovascular disease [17, 20-22]. With other comorbidities, the association is related to common risk factors including smoking, excess alcohol use, recreational drug use, and poverty [23, 24]. To date, there are a limited number of studies that have comprehensively evaluated comorbidity among people with HCV. For example, Stasi et al. [25] used a studyspecific clinical database for patients from 16 hospitals in Tuscany to look at comorbidities amongst $\mathrm{HCV}$ patients, Sicras-Mainar et al. [26] conducted a similar study based on medical records at 8 primary care centres in Spain, and Lauffenburger et al. [27] used a US commercial claims database for the same purpose. These studies showed significant comorbidities such as diabetes, dyslipidaemia and hypertension amongst $\mathrm{HCV}$ patients, but did not report on multiple comorbidities. Liu et al. [28] reported on multiple comorbidities in their study of Taiwanese adult HCV patients using a physician-completed survey, as did Ruzicka et al. [29] in their study of Japanese adult HCV patients using a medical claims database and Louie et al. [30] in their study of patients with chronic HCV using a US medical claims database. All of these studies showed a significant prevalence of multiple comorbidities (e.g., more than $50 \%$ of Japanese $\mathrm{HCV}$ patients had $\geq 4$ comorbidities, and $52 \%$ of US patients reported $6-15$ ), with the latter two showing this to be greater than amongst matched controls (e.g., only $29.5 \%$ of Japanese non$\mathrm{HCV}$ patients had $\geq 4$, and over $47 \%$ of US patients reported $\leq 5$ comorbidities). However, these studies either did not use validated or standardized ascertainment methods, or the diagnoses focused on were illdefined.

In the past, both mental health and physical health comorbidity, and their multimorbidity, may have hindered HCV treatment with interferon and ribavirinbased therapy given the long duration of treatment, the need for weekly subcutaneous injections, and the heavy burden of side effects and toxicities [31, 32]. More recently, Direct Acting Antivirals (DAA) have provided the opportunity to treat people in much less time, with next to no side effects, and with cure rates that are well over 90\% [33-36]. However, whether multimorbidity remains a barrier to treatment initiation and successful antiviral treatment outcome in the DAA era is unclear. In two cohort evaluations of DAA recipients, the presence of comorbidities predicted diminished antiviral treatment outcomes [37, 38].

In this study, we uniquely used diverse HCV clinical cohort data linked to robust health administrative databases from a universal, single-payer healthcare system. We used these data to comprehensively i) describe the prevalence of physical and mental health comorbidities and their multimorbidity in a cohort of people living with $\mathrm{HCV}$; ii) compare this prevalence to an age-, sex-, and geographically-matched population without $\mathrm{HCV}$; iii) examine the association between multimorbidity and $\mathrm{HCV}$ treatment with interferon- and DAA-based antiviral therapy initiation, and; iv) among those treated with DAA, examine the association between multimorbidity and cure. The role of comorbid substance use on $\mathrm{HCV}$ antiviral treatment uptake and outcome use was specifically assessed.

\section{Methods}

\section{Study design}

This was a retrospective cohort study of patients with $\mathrm{HCV}$ at The Ottawa Hospital Viral Hepatitis Program (TOHVHP).

\section{Data sources}

We used data from TOHVHP, a publicly funded, academic tertiary care-based regional referral centre for viral liver disease care in Ottawa, Canada. This is the primary referral centre for $\mathrm{HCV}$ in Eastern Ontario, irrespective of stage of disease. The cohort consists of demographic, clinical, and laboratory data collected from consenting participants who receive care in TOHVHP clinics (Ottawa Health Science Network Research Ethics Board: 2004-196). Participants agreed to linkage and analysis of non-nominal data.

We linked TOHVHP data to provincial health administrative data at ICES, an independent non-profit research institute whose legal status under Ontario's health information privacy laws allows it to collect and analyze health care and demographic data, without consent, for health system evaluation and improvement. The following ICES datasets were linked using unique encoded identifiers and analyzed at ICES: the Registered Persons Database, an electronic registry of demographic and mortality data for residents eligible for provincial health care; the Ontario Health Insurance Program (OHIP) billing claims dataset, which captures services 
provided by about $95 \%$ of physicians in Ontario; the Discharge Abstract Database for all hospital admission and discharge data; the Ontario Mental Health Reporting System for all admissions to designated mental health beds; CONTACT (eligibility summaries and yearly health services contact); the Ontario Cancer Registry for data on patients with diagnoses of cancer; and the Immigration, Refugee and Citizenship Canada (IRCC) Permanent Resident database, which includes the country of birth of immigrants who landed in Ontario as of 1986. We also used 2011 Statistics Canada Census data to generate neighborhood income quintiles by linking postal code of residence to the mean household income.

\section{Participants}

TOHVHP and ICES datasets were linked either deterministically, using unique, encoded identifiers derived from participants' OHIP numbers, or probabilistically, based on a number of other personal identifiers (first and last name, date of birth, sex, postal code). We included all TOHVHP patients with a first visit from April 1, 2000 to the index date of April 1, 2017. We excluded participants for the following reasons: less than age 18 years at index, invalid OHIP card at index, death date in ICES data before index date, invalid sex or age in ICES data, missing or out-of-province postal code, or not seen by the program in the 5 years prior to index date.

To compare TOHVHP participants to the general Ontario population, we randomly selected control individuals, matched on age, sex, and public health unit, in a $5: 1$ ratio.

\section{Outcomes}

To ascertain comorbidities, we used validated algorithms developed at ICES to determine the prevalence of the following chronic conditions: acute myocardial infarction (AMI) [39], asthma [40], congestive heart failure (CHF) [41], chronic obstructive pulmonary disease (COPD) [42], dementia [43], diabetes [44], hypertension [45], HIV [46] and rheumatoid arthritis [47]. As with other multimorbidity studies [48, 49], for conditions where a derived ICES cohort did not exist, we adopted a similar approach (i.e. the presence of any one inpatient hospital diagnostic code (DAD data) or two or more outpatient physician billing codes (OHIP data) within a 2 year period using relevant ICD- 9 and ICD-10 codes) to define the following chronic conditions: cardiac arrhythmia, osteoarthritis, osteoporosis, renal failure, and stroke, as well as for mental health conditions and substance use disorders. (Appendix 1 in Table 3) [48-54]. We determined the prevalence of any cancer using the OCR. Liver failure and liver transplant were ascertained if one ICD9 or ICD10 code was billed in OHIP or DAD in the previous 10 years. (Appendix 1 in Table 3).

We used disease count to measure the prevalence of multimorbidity [55]. Physical multimorbidity was defined as the presence of two or more listed physical chronic conditions, and physical-mental health multimorbidity was defined as a combination of both at least one mental health condition and at least one physical chronic health condition. Among patients in the $\mathrm{HCV}$ group, this multimorbidity is in addition to $\mathrm{HCV}$ as their index condition.

\section{Variables}

We used the following sources to examine cohort characteristics: (1) RPDB: age, sex; (2) IRCC: immigration status, categorized as immigrant from a country with a generalized $\mathrm{HCV}$ epidemic, immigrant from a non-HCV endemic country, or a long-term resident, as IRCC files date back only to 1985 . Countries with intermediate high to high prevalence (rates greater than 1.3\% based on $\mathrm{HCV}$ serology or viremia criteria) were considered HCV-endemic countries [56, 57]; (3) TOHVHP: time from $\mathrm{HCV}$ diagnosis, $\mathrm{HCV}$ treatment status, categorized as treated with a DAA, an interferon-based regimen, or neither. Any interferon recipient, irrespective of coadministered RBV and/or DAA was classified in the interferon grouping. Only those on interferon-free regimens were classified as DAA recipients. Cure was determined by the presence of at least one blood test demonstrating the absence of HCV RNA at least 12 weeks following completion of HCV antiviral therapy.

\section{Statistical analyses}

We used descriptive statistics to describe the demographic and clinical characteristics, and compared the groups using two-sample t-tests for continuous variables and chi-squared tests for categorical variables. We calculated the prevalence of individual physical and mental health comorbidities, physical multimorbidity, and physical-mental health multimorbidity. We used direct standardization to calculate age- and sex-standardized prevalence rates using the Canadian 2011 population as the reference standard. We estimated the comparative prevalence ratios of these rates, with $95 \%$ confidence intervals calculated using the formula provided by Breslow and Day [58]. We also compared the prevalence of treatment with interferon and DAA among those with and without multimorbidity by age group and the prevalence of cure among those treated with DAA by age group. We further stratified these associations for both men and women. Finally, given the anticipated prevalence of substance use disorders in our population, we also stratified treatment and cure prevalence among those specifically with and without substance use 
disorders. We defined statistical significance a priori at a $p$-value of 0.05 . All statistical analyses were performed using SAS version 9.4 (SAS Institute, Cary, North Carolina).

\section{Results}

Most TOHVHP patients (90.4\%) were successfully linked to ICES data. After exclusions, our HCV group comprised 1209 individuals (Additional file 1: Figure S1). The demographic and clinical characteristics of the $\mathrm{HCV}$ group and the matched general population $(n=$ 6045 ) are shown in Table 1 . The mean age was 54.5 years and $64.7 \%$ were male. In both groups, approximately $13 \%$ of participants had immigrated to Canada. Among the HCV group, 4.4\% were HIV co-infected and $0.5 \%$ were hepatitis B virus co-infected. Of those with known fibrosis stage data, 33.2\% (309/932) were cirrhotic. Approximately one-quarter (27.2\%) were $\mathrm{HCV}$ antiviral treatment naïve, $4.2 \%$ had been treated without achieving SVR, 57.1\% had received treatment and achieved a cure, and $11.4 \%$ had missing treatment data. Among those treated, $76.0 \%$ received DAA-containing regimens. Compared to the general population, HCVinfected individuals had significantly greater comorbidity, and had higher prevalence of multimorbidity $(29.9 \%$ vs $20.8 \%, p<0.001)$ and physical-mental health multimorbidity $(24.7 \%$ vs $9.5 \%, p=0.001)$.

Table 2 presents the age- and sex-standardized prevalence rates for the two groups, along with the prevalence rate ratios and $95 \%$ confidence intervals. The prevalence in the HCV group was significantly higher for asthma (prevalence ratio (PR) 1.32; 95\% confidence interval (CI) 1.06 to 1.64 ), any cancer ( $\mathrm{PR}=1.76 ; 95 \% \mathrm{CI}, 1.22$ to 2.55), $\mathrm{COPD}$ ( $\mathrm{PR}=2.42 ; 95 \% \mathrm{CI} 1.73$ to 3.39 ), diabetes $(\mathrm{PR}=1.32 ; 95 \% \mathrm{CI} 1.06$ to 1.64$)$, and renal failure $(\mathrm{PR}=$ 2.92; $95 \%$ CI 1.90 to 4.48), but not for cardiac outcomes (arrhythmias, congestive heart failure, chronic coronary syndrome). The burden of all mental health conditions including non-psychotic mood and anxiety disorders, other mental health illnesses, and substance use were significantly more prevalent in the $\mathrm{HCV}$ group ( $\mathrm{PR}=$ 2.22; $95 \%$ CI 1.86 to 2.64 , PR $=2.71$; $95 \%$ CI 2.06 to 3.55 , and $\mathrm{PR}=26.50 ; 95 \% \mathrm{CI} 18.35$ to 38.27 , respectively). Liver failure was significantly more prevalent in the HCV group (PR $=6.63$; 95\% CI 2.72 to 11.81 ). The number of liver cancers and liver transplants were greater in the HCV group, with 30 and 15 affected participants respectively, but numbers in the comparison population were too small to calculate prevalence ratios. Finally, multimorbidity and combined physical-mental health comorbidity were significantly more prevalent in the $\mathrm{HCV}$ group $(\mathrm{PR}=1.38$; $95 \% \mathrm{CI} 1.38$ to 1.58 and $\mathrm{PR}=$ $2.71 ; 95 \%$ CI 2.29 to 3.20 , respectively).
Figure 1a shows the prevalence of multimorbidity by age category for both cohorts. Multimorbidity was significantly greater among $\mathrm{HCV}$ patients for all age groups until age 66 years, with differences most striking in the early age categories. This trend persisted when the groups were stratified by sex (Fig. $1 \mathrm{~b}$ and $\mathrm{c}$ ).

Figure $2 \mathrm{a}$ and $\mathrm{b}$ show the prevalence of treatment with interferon and DAA among participants with and without multimorbidity, by age group. Treatment prevalence did not significantly vary by whether the individual had multimorbidity at any age among either the 178 people treated with interferon or the 563 people treated with DAA. These trends generally held when the group was stratified by age, although among those treated with interferon, compared to those without multimorbidity, statistically significantly more men aged 56-65 years were treated $(63.2 \%$ vs $42.6 \%, p=0.03$, data not shown).

Figure 3 shows the prevalence of cure among participants treated with DAA among people with $\mathrm{HCV}$ with and without multimorbidity, by age group. Among the 563 people treated with DAA, 95.6\% $(n=538)$ were cured, and cure from DAA treatment did not differ among those with and without multimorbidity. This trend held when the group was stratified by sex (data not shown). Note that small cell sizes made estimates difficult for some age groups.

Figure $4 \mathrm{a}$ and $\mathrm{b}$ show the prevalence of treatment with interferon and DAA among people with HCV with and without substance use disorders, by age group. Among the 178 people treated with interferon, treatment prevalence generally did not significantly vary by whether the individual had substance use disorder except among individuals aged 36 to 45 years, among whom a lower proportion with substance use disorder received treatment treated $(13.6 \%$ vs $42.9 \%, p=0.02)$. Among the 563 people treated with DAA, treatment prevalence was significantly lower among those with substance use disorder aged 46 to 55 years and 56 to 65 years $(41.1 \%$ vs $64.3 \%, p=0.001$ and $58.3 \%$ vs $79.9 \%, p=0.003$, respectively).

Figure 5 shows the prevalence of cure among participants with and without substance use disorder treated with DAA. Among the 563 individuals treated with DAA, the proportion of those cured did not differ among those with and without substance use disorder. Note that small cell sizes made estimates unstable for some age groups (data not shown).

\section{Discussion}

In our study of a clinical cohort linked to health administrative data with validated chronic disease ascertainment algorithms, we found individual comorbidity burden to be greater among people with $\mathrm{HCV}$ 
Table 1 Demographic and clinical characteristics of TOHVHP HCV group and the general population

\begin{tabular}{|c|c|c|c|}
\hline \multirow[t]{3}{*}{ Variable } & \multirow{3}{*}{$\begin{array}{l}\text { TOHVHP HCV group } \\
N=1209 \\
N(\%)\end{array}$} & General population & \multirow{3}{*}{$\begin{array}{l}p- \\
\text { value }\end{array}$} \\
\hline & & $N=6045$ & \\
\hline & & $N(\%)$ & \\
\hline Age (yrs) (mean, SD) & $54.54 \pm 11.42$ & $54.54 \pm 11.41$ & 1.00 \\
\hline Age (yrs) (median, IQR) & $56(49-62)$ & $56(49-62)$ & 1.00 \\
\hline \multicolumn{4}{|l|}{ Age category } \\
\hline $16-25$ & $15(1.2 \%)$ & $75(1.2 \%)$ & 1.00 \\
\hline $26-35$ & $77(6.4 \%)$ & $385(6.4 \%)$ & \\
\hline $36-45$ & $127(10.5 \%)$ & $635(10.5 \%)$ & \\
\hline $46-55$ & $369(30.5 \%)$ & $1845(30.5 \%)$ & \\
\hline $56-65$ & $464(38.4 \%)$ & $2320(38.4 \%)$ & \\
\hline $66-75$ & $122(10.1 \%)$ & $610(10.1 \%)$ & \\
\hline $75+$ & $35(2.9 \%)$ & $175(2.9 \%)$ & \\
\hline Sex & & & 1.00 \\
\hline Male & $782(64.7 \%)$ & $3910(64.7 \%)$ & \\
\hline Female & $427(35.3 \%)$ & $2135(35.3 \%)$ & \\
\hline Immigration status & & & 0.49 \\
\hline Canadian citizen & $1056(87.3 \%)$ & $5290(87.5 \%)$ & \\
\hline Immigrant from HCV endemic country & $54(4.5 \%)$ & $230(3.8 \%)$ & \\
\hline Immigrant from non-endemic country & $99(8.2 \%)$ & $525(8.7 \%)$ & \\
\hline HCV mono-infection & 1151 (95.2\%) & - & \\
\hline HCV-HIV co-infection & $53(4.4 \%)$ & - & \\
\hline HCV-HBV co-infection & $6(0.5 \%)$ & - & \\
\hline \multicolumn{4}{|l|}{ Time from HCV diagnosis } \\
\hline$<5$ years from index date & $124(10.3 \%)$ & - & \\
\hline 5 to $<10$ years from index date & $123(10.2 \%)$ & - & \\
\hline $10+$ years from index date & $263(21.8 \%)$ & - & \\
\hline Missing & $699(57.8 \%)$ & - & \\
\hline \multicolumn{4}{|l|}{ Treatment status $^{\mathrm{a}}$} \\
\hline Treated and cured & $690(57.1 \%)$ & - & \\
\hline Treated and not cured & $51(4.2 \%)$ & - & \\
\hline Never treated & $329(27.2 \%)$ & - & \\
\hline Missing & $139(11.4 \%)$ & & \\
\hline \multicolumn{4}{|l|}{ HCV treatment type $(n=741)$} \\
\hline Direct acting antiviral (DAA) & $563(76.0 \%)$ & - & \\
\hline Interferon (IFN) & $178(24.0 \%)$ & - & \\
\hline \multicolumn{4}{|l|}{ Highest fibrosis score } \\
\hline 1 & $332(27.5 \%)$ & - & \\
\hline 2 & $171(14.1 \%)$ & - & \\
\hline 3 & $120(9.9 \%)$ & - & \\
\hline 4 & $309(25.6 \%)$ & - & \\
\hline Missing & $277(22.9 \%)$ & - & \\
\hline Prevalence of multimorbidity (at least two physical conditions) & $361(29.9 \%)$ & $1259(20.8 \%)$ & $<0.001$ \\
\hline Prevalence of physical-mental health multimorbidity & $299(24.7 \%)$ & $574(9.5 \%)$ & $<0.001$ \\
\hline
\end{tabular}

a $139(11.5 \%)$ individuals could not be classified into any of the treatment status categories. Of these $33(2.7 \%)$ were treated but had not completed their post-treatment bloodwork and cured status could not be determine, $72(6.0 \%)$ were potentially LTFU, and $34(2.8 \%)$ were unaccounted for (not found in either treatment database, but no record of lab test results (VL bloodwork)) 
than the general population. This was especially true for substance use, mental health, and liver-related diseases. In addition, we found that the multimorbidity of these conditions was significantly greater for people with HCV, including both physical and combined physical and mental health multimorbidity. This finding was most significant among younger age groups and persisted up until age 66 years for both men and women. We also found that multimorbidity was not associated with receiving interferon-containing or DAA treatment, nor with achieving cure with DAA treatment. However, people with substance use disorder in their middle age were less likely to receive treatment even with DAA. As there is no known validated algorithm for HCV ascertainment using administrative data, our study is the first to our knowledge to use combined cohort and population-based data to determine multimorbidity among a cohort of people living with $\mathrm{HCV}$ and to compare this to a general, representative population.

We found an increase in the prevalence of several chronic conditions among people living with $\mathrm{HCV}$. Substance use is a well-established risk factor for HCV exposure and the prevalence of concomitant mental health conditions is recognized as being very high in those with $\mathrm{HCV}$ infection [59]. However, we found even higher prevalence of these conditions in our cohort than other populations. For example, we found substance use disorders among nearly one-third of the $\mathrm{HCV}$ patients in our cohort, whereas other studies found $4-25 \%$ prevalence. Similarly we found mood and anxiety disorders among one-third of $\mathrm{HCV}$ patients, compared to $13.9-23.7 \%$ for depression in other studies $[26,27,30]$. One reason for this could be that our

Table 2 Comorbidity and multimorbidity prevalence between TOHVHP HCV group and the general population (age and sex standardized to 2011 Ontario population)

\begin{tabular}{|c|c|c|c|c|c|}
\hline \multirow[t]{3}{*}{ Condition } & \multirow{2}{*}{\multicolumn{2}{|c|}{$\begin{array}{l}\text { TOHVHP HCV group } \\
N=1209\end{array}$}} & \multirow{2}{*}{\multicolumn{2}{|c|}{$\begin{array}{l}\text { General population } \\
N=6045\end{array}$}} & \multirow{3}{*}{$\begin{array}{l}\text { HCV:General popn } \\
\text { Prevalence ratio }(95 \% \mathrm{Cl})\end{array}$} \\
\hline & & & & & \\
\hline & $n$ & Prevalence $(\%)$ & $n$ & Prevalence (\%) & \\
\hline Acute myocardial infarction ${ }^{a}$ & $<6$ & - & $<17$ & - & - \\
\hline Asthma & 206 & 19.40 & 746 & 14.74 & $1.32(1.06-1.64)$ \\
\hline Cancer (any)* & 83 & 7.78 & 241 & 4.42 & $1.76(1.22-2.55)$ \\
\hline Cardiac arrhythmia & 31 & 2.60 & 258 & 4.19 & $0.62(0.37-1.06)$ \\
\hline Chronic obstructive pulmonary disease* & 97 & 7.78 & 137 & 3.22 & $2.42(1.73-3.39)$ \\
\hline Congestive heart failure* & 46 & 3.79 & 122 & 3.14 & $1.21(0.77-1.88)$ \\
\hline Chronic coronary syndrome & 89 & 5.61 & 422 & 5.79 & $0.97(0.68-1.38)$ \\
\hline Dementia $^{a}$ & $<13$ & - & 48 & - & - \\
\hline Diabetes & 207 & 13.27 & 819 & 10.07 & $1.32(1.06-1.64)$ \\
\hline Hypertension & 364 & 24.97 & 1746 & 23.14 & $1.08(0.91-1.27)$ \\
\hline Non psychotic mood and anxiety disorders & 330 & 31.24 & 805 & 14.08 & $2.22(1.86-2.64)$ \\
\hline Other mental illness & 157 & 13.35 & 308 & 4.93 & $2.71(2.06-3.55)$ \\
\hline Osteoporosis & 35 & 3.11 & 157 & 3.35 & $0.93(0.55-1.58)$ \\
\hline Rheumatoid arthritis & 22 & 1.19 & 55 & 0.97 & $1.23(0.67-2.24)$ \\
\hline Renal failure* & 87 & 6.19 & 97 & 2.12 & $2.92(1.90-4.48)$ \\
\hline Stroke ${ }^{*}$ & 22 & 1.72 & 101 & 1.83 & $0.94(0.49-1.81)$ \\
\hline Substance use disorder* & 287 & 32.83 & 88 & 1.24 & $26.50(18.35-38.27)$ \\
\hline Hepatocellular cancer ${ }^{a}$ & 30 & - & $<=6$ & - & - \\
\hline Liver failure* & 71 & 4.29 & 38 & 0.65 & $6.63(3.72-11.81)$ \\
\hline Liver transplant ${ }^{a}$ & 15 & - & 0 & - & - \\
\hline Multimorbidity (at least two physical conditions) & 554 & 39.20 & 2053 & 28.48 & $1.38(1.20-1.58)$ \\
\hline Physical-mental health multimorbidity & 396 & 32.24 & 792 & 11.91 & $2.71(2.29-3.20)$ \\
\hline
\end{tabular}

${ }^{a}$ indicate that direct standardization could not be performed due to sparse age-sex cell sizes. In such cases, direct standardization was performed Note: Prevalences were standardized using the $\mathbf{2 0 1 1}$ Ontario Population, the $\mathrm{n}$ is the true size from each group Bold faced font indicates statistically significant at the 0.05 level

*Significant Finding 

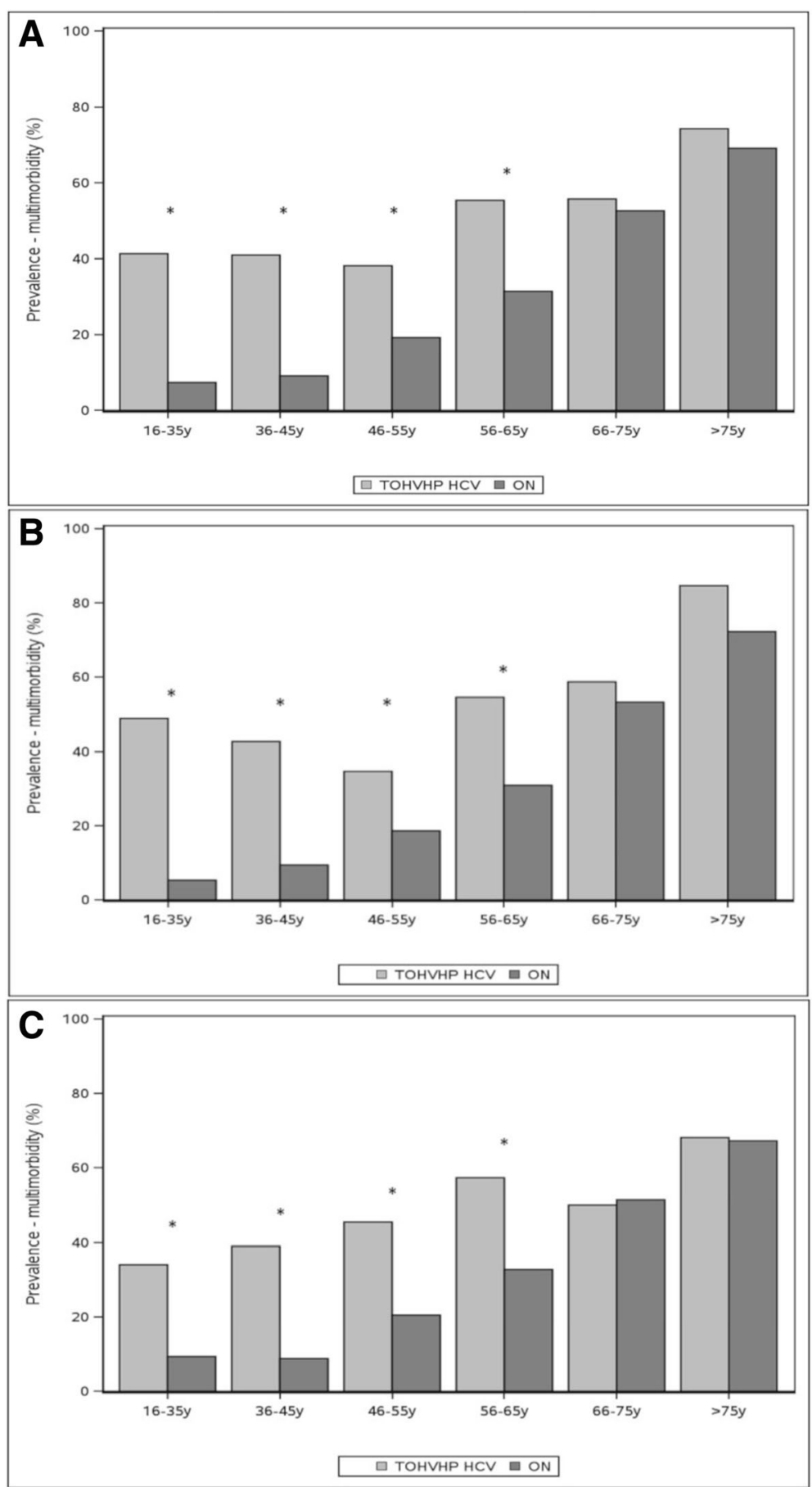

Fig. 1 a Multimorbidity prevalence ( $>=2$ conditions) by age group among men and women in the TOHVHP HCV group $(n=1209)$ versus the general population ( $n=6045$ ). b Multimorbidity prevalence $(>=2$ conditions) by age group among men in the TOHVHP HCV cohort $(n=782)$ versus the Ontario cohort $(n=3910)$. c Multimorbidity prevalence ( $>=2$ conditions) by age group among women in the TOHVHP HCV cohort $(n=427)$ versus the Ontario cohort $(n=2135) .{ }^{*} P<0.05$

setting has universal access to care, which could have facilitated patient access for these conditions. In addition, the consequences of chronic $\mathrm{HCV}$ infection include liver failure, hepatocellular carcinoma, and the need for liver transplantation [60]. As such, our finding that liver-related disease is higher in those living with $\mathrm{HCV}$ compared to the general population is not surprising.

We also found that the prevalence of several nonhepatic conditions was greater among people with HCV. 

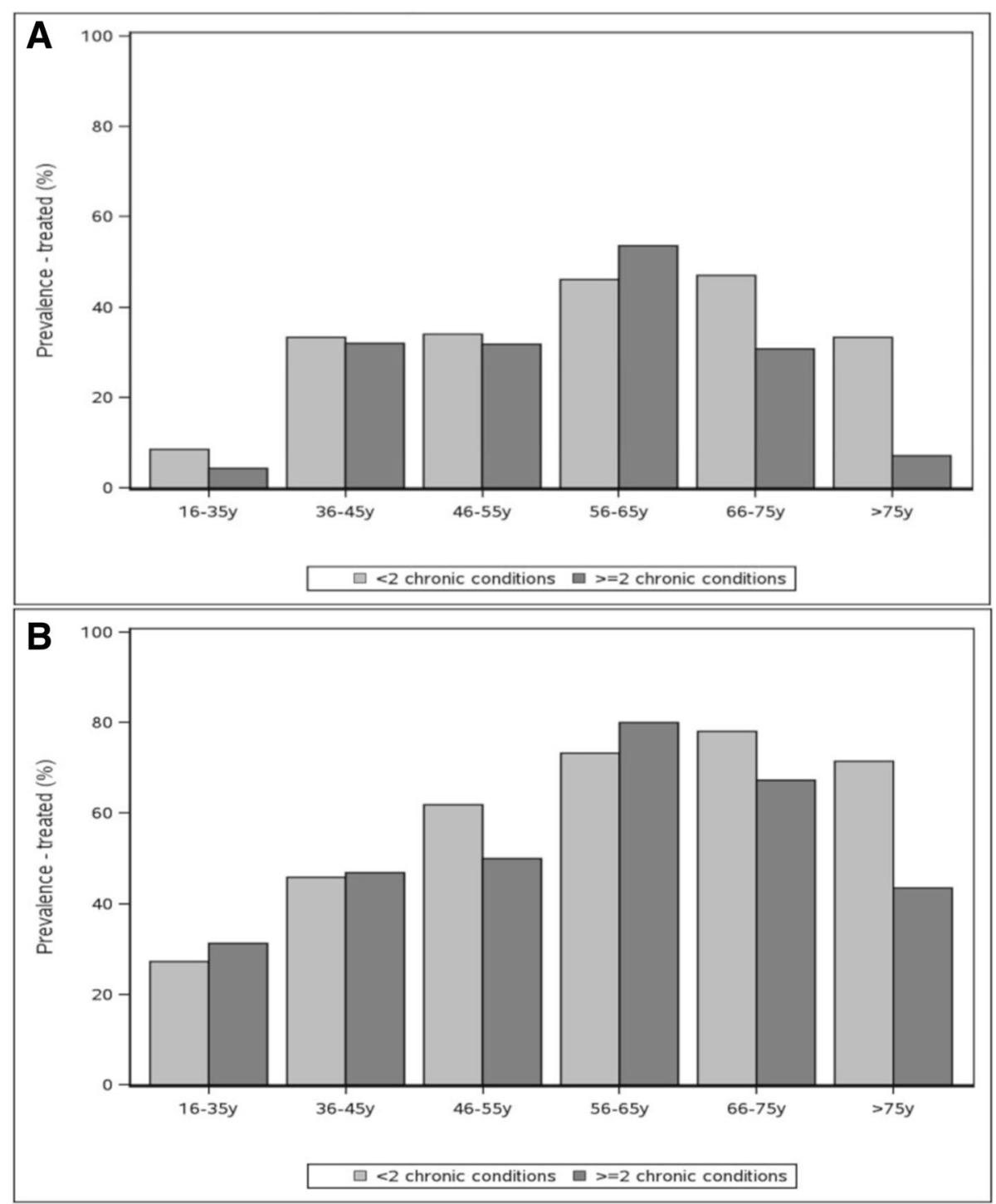

Fig. 2 a Treatment prevalence by age group and multimorbidity ( $>=2$ conditions) among participants in the TOHVHP HCV cohort - Treated with interferon $(n=178)$. $\mathbf{b}$ Treatment prevalence by age group and multimorbidity ( $>=2$ conditions) among participants in the TOHVHP HCV cohort - Treated with DAA $(n=563)$

This was true for conditions known to have causal relationships with $\mathrm{HCV}$, including diabetes, some cancers, and chronic renal failure [5-10, 15-19], although our estimates for these conditions were generally lower than those in other studies with less stringent, unvalidated methods of chronic disease ascertainment $[26,27,29,30]$ or from clinical charts [25]. For example, we found the prevalence of diabetes in our cohort was $13.27 \%$, compared to $13.8-26.1 \%$ in other studies [25-27, 29, 30]. We also found greater prevalence of lung conditions including asthma and COPD, which were, when combined, higher than some [26, 29] and lower [27] than prevalences reported in studies with less robust definitions, likely due to overlap between these conditions and their relationship with smoking. We also did not find evidence of increased prevalence of any cardiovascular conditions among people with $\mathrm{HCV}$ compared to the general population, including both acute (myocardial infarction, stroke) or chronic (hypertension, chronic coronary syndrome, congestive heart failure, arrhythmia) conditions. This is in contrast to other studies that found increased prevalences of these conditions among people with HCV [26-29], although, again, our condition ascertainment was more rigorous. For example, we found hypertension among one quarter of our $\mathrm{HCV}$ patients, whereas other studies reported prevalence of $31.4-40.1 \%$ $[26,27,29,30]$. Again, we note that the comparator studies used a variety of ascertainment methods for defining 


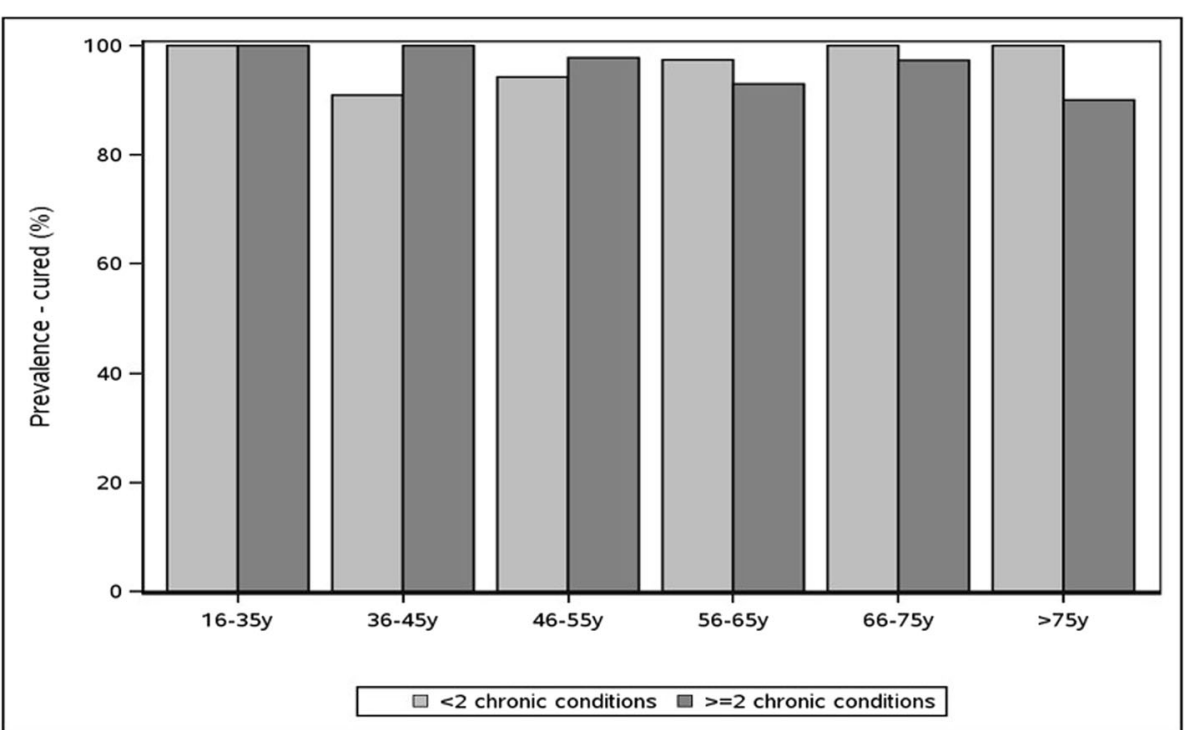

Fig. 3 Cured prevalence by age group and multimorbidity ( $>=2$ conditions) among participants treated with DAA in the TOHVHP HCV cohort $(n=563)$

comorbidity, the majority of which have not been validated, or included symptom-based diagnoses such as pain, making comparisons challenging.

Importantly, we also found that the multimorbidity of these conditions, including combined physical and mental health multimorbidity, was also particularly high in those living with $\mathrm{HCV}$ infection. To our knowledge, only one other study has quantified this burden [30]: these authors found slightly greater proportions of multiple conditions. However, ascertainment of these conditions was not validated and many of those conditions, including those at greatest prevalence contributing to multimorbidity counts, were symptom-based, such as abdominal pain, back problems, and fatigue, thus may not have the same implications for engaging people in care and treatment.

In our study, multimorbidity was not associated with initiation of either interferon or DAA regimens. This result was surprising, as interferon is well known for producing and/or exacerbating underlying medical and mental health conditions, many of which have been considered relative or absolute contraindications to initiating interferon-based therapy [61]. We suspect this reflects our practice of reserving interferon-based treatment to those with more advanced liver fibrosis, who would have been older and more likely to have multimorbidity as demonstrated by our analysis. A major advantage of DAA therapy is that there are few contraindications, even in those with advanced liver disease or other comorbidities [62], which supports our finding that multimorbidity was not associated DAA-based treatment initiation. While, in at least one study, early discontinuation of interferon-free therapy was predicted in part by comorbidity burden [38], in our analysis the proportion of DAA-treated patients achieving a SVR was unrelated to prevalence of multimorbidity. Finally, when we restricted our analyses to people with substance use disorders, those who were middle-aged were less likely to receive DAA, although these individuals were equally likely to achieve cure. Others in similar settings have also noted this disparity [63]. This finding is of concern given that DAA therapy is reimbursed by our provincial formulary for nearly all patients and that the average age of people with $\mathrm{HCV}$ who use drugs in Canada is in the mid to late forties range $[63,64]$. It is critical to develop policies and strategies that facilitate DAA uptake and completion in those facing barriers to treatment $[65,66]$.

A strength of our study is that we used a combination of rich data from a diverse cohort of people living with $\mathrm{HCV}$ in a broad geographic region combined with robust population-level data for comorbidity ascertainment. In addition, recognizing that mental health comorbidity, in particular substance use disorder, may be particularly high among people living with $\mathrm{HCV}$, we stratified our findings to include those with and without these conditions so as not to overestimate the impact of their prevalence on all people living with HCV. Nevertheless, there are limitations. Although we used validated algorithms to identify comorbidities, our estimates are restricted to people who are diagnosed and receiving care. We also could not ascertain treatment outcomes among people who were lost to followup from care, and in particular among interferon-based 

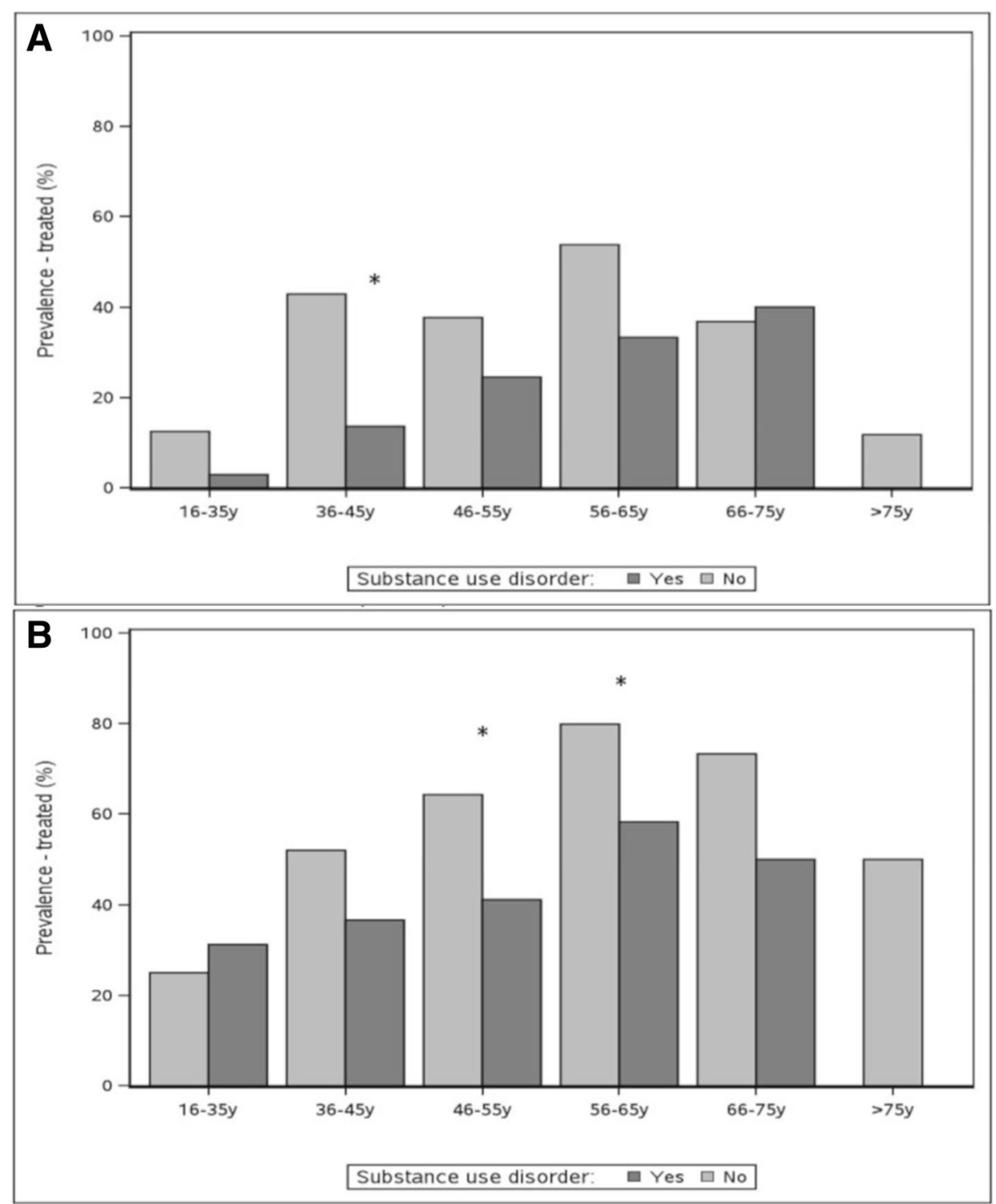

Fig. 4 a Treatment prevalence by age group among participants with and without substance use disorder in the TOHVHP HCV cohort - Treated with IFN $(n=178) \mathbf{b}$ Treatment prevalence by age group among participants with and without substance use disorder in the TOHVHP HCV cohort - Treated with DAA $(n=563)$

treatment recipients for whom treatment outcomes were incomplete. This would introduce bias in our results if the multimorbidity of those lost to follow up had significantly different morbidity from those who were retained for analysis. Evaluation of comorbidity as a function of liver fibrosis stage would have been revealing. However, our dataset did not allow for this analysis. Finally, our study setting is one of single payer, universal care, which likely optimizes disease ascertainment based on diagnosis codes but may not be generalizable to other settings. Given the retrospective nature of this analysis we were able to identify associations but not establish causality.
People living with HCV have a higher prevalence of many comorbidities as well as both physical and physical-mental health multimorbidity compared to the Ontario population. Middle-aged individuals with substance use disorder were less likely to receive treatment, even in the DAA era. In addition to well-known reductions in mortality and liver-specific comorbidity, $\mathrm{HCV}$ treatment has also been shown to reduce future comorbidity, including diabetes, renal disease, cardiovascular disease, mental and cognitive health, and quality of life [67-73]. As such, our findings support current calls for taking a broad, inclusive approach to offering HCV antiviral therapy regardless of physical and mental health 


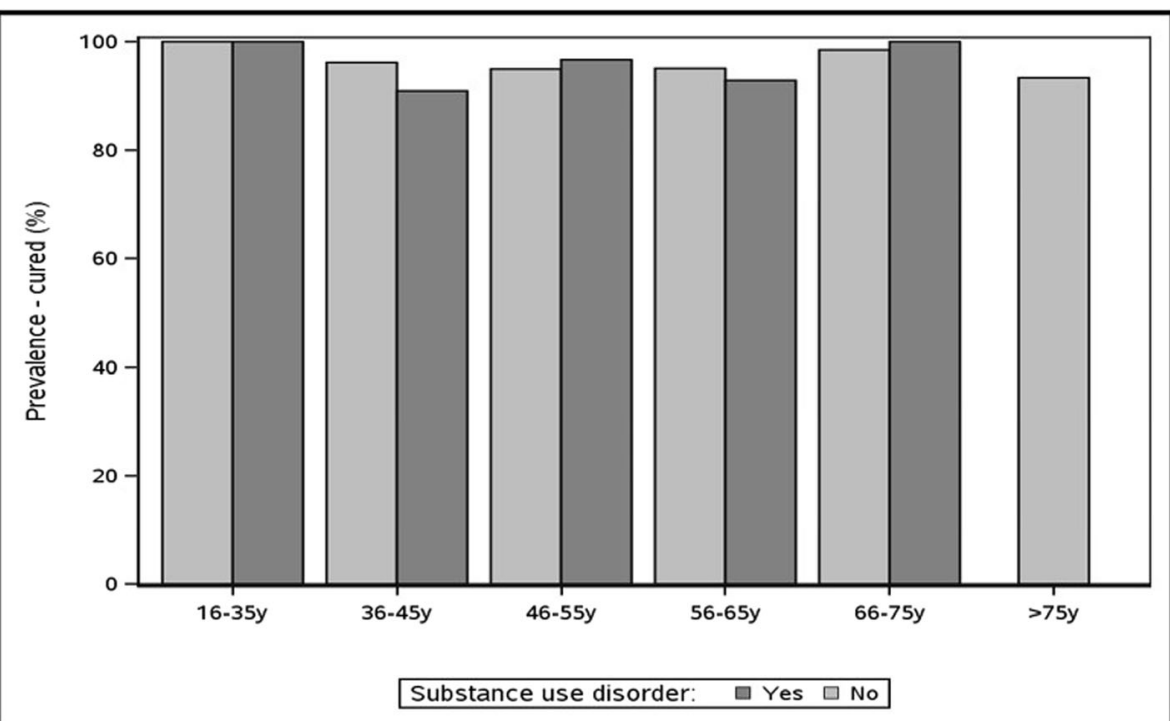

Fig. 5 Cured prevalence by age group among participants with and without substance use disorder treated with DAA in the TOHVHP HCV cohort $(n=563)$

comorbidity and mode of HCV transmission, including injection drug use. With the evidence that the management of chronic diseases is most effectively and economically provided in well-supported primary care settings $[74,75]$, our findings call for integrated, comprehensive, community-oriented approaches to HCV care delivery. Specific strategies may include involving peers in care, case management, integration of HCV care with substance use, social service delivery, primary care services [76], use of telehealth services [77], and selfmanagement strategies [78-80].

\section{Conclusions}

People with HCV have a higher prevalence of comorbidity and multimorbidity compared to the general population. While $\mathrm{HCV}$ treatment was not associated with multimorbidity, people with substance use disorder were less likely to be treated. Given the capacity for treatment to prevent and mitigate the effects of comorbidity among people with $\mathrm{HCV}$, our results point to the need for integrated, comprehensive models of care delivery for people with HCV with a particular emphasis on mental health and addictions care.

\section{Appendix}

Table 3 ICD codes used to define chronic conditions

\begin{tabular}{|c|c|c|c|}
\hline Condition & $\begin{array}{l}\text { ICD-O } \\
\text { (topographical } \\
\text { codes) }\end{array}$ & ICD-9 & ICD-10 \\
\hline \multicolumn{4}{|l|}{ Cancer (any) (OCR - 10 year lookback) } \\
\hline Hepatocellular cancer & $\begin{array}{l}8170,8171,8172 \\
8173,8174,8175\end{array}$ & & C22.0 \\
\hline \multicolumn{4}{|l|}{$\begin{array}{l}\text { Mental health diagnoses (10 year } \\
\text { lookback for hospitalizations, } 2 \text { year } \\
\text { lookback for OHIP billings) }\end{array}$} \\
\hline $\begin{array}{l}\text { Non-psychotic mood and anxiety } \\
\text { disorders }^{\mathrm{a}}\end{array}$ & & 296, 300, 309, 311 & $\begin{array}{l}\text { F30, F31, F32, F33, F341, F348, } \\
\text { F349, F38, F39, F40, F41, F42, } \\
\text { F431, F432, F438, F44, F450, F451, } \\
\text { F452, F48, F530, F680, F930, F99 }\end{array}$ \\
\hline $\begin{array}{l}\text { Other mental illnesses }{ }^{\text {a }} \text { (including } \\
\text { schizophrenia, } \\
\text { delusions, and other psychoses; } \\
\text { personality disorders;) }\end{array}$ & & $\begin{array}{l}291,292,295,297, \\
298,299,301,302, \\
305,306,307,313, \\
314,315,319 ;\end{array}$ & $\begin{array}{l}\text { F2, F04, F050, F058, F059, F060, } \\
\text { F061, F062, F063, F064, F07, F08, } \\
\text { F340, F35, F36, F37, F430, F439, } \\
\text { F453, F454, F458, F46, F47, F49, } \\
\text { F50, F51, F52, F531, F538, F539, } \\
\text { F54, F55, F56, F57, F58, F59, F60, }\end{array}$ \\
\hline
\end{tabular}


Table 3 ICD codes used to define chronic conditions (Continued)

\begin{tabular}{|c|c|c|}
\hline Condition & $\begin{array}{l}\text { ICD-O } \\
\text { (topographical } \\
\text { codes) }\end{array}$ & ICD-9 \\
\hline $\begin{array}{l}\text { Substance use disorder }{ }^{\mathrm{a}} \text { (10 year lookback } \\
\text { for hospitalizations) }\end{array}$ & & 303,30 \\
\hline \multicolumn{3}{|l|}{$\begin{array}{l}\text { Liver failure (one code ever is sufficient for } \\
\text { diagnosis) }\end{array}$} \\
\hline Hepatic coma & & 572.2 \\
\hline Hepatorenal syndrome & & 572.4 \\
\hline Varices with bleeding all diagnoses & & 456.0 \\
\hline $\begin{array}{l}\text { Esophageal varices - other diseases } \\
\text { with bleeding }\end{array}$ & & 456.2 \\
\hline Ascites & & 789.5 \\
\hline Peritonitis & & 567.2 \\
\hline
\end{tabular}

Hepatic failure NEC

Acute and subacute hepatic failure

$\mathrm{K} 72$

K72.0

K72.00

Acute and subacute hepatic failure without coma

Acute and subacute hepatic failure with coma

Chronic hepatic failure

Chronic hepatic failure without coma

Chronic hepatic failure with coma

Hepatic failure, unspecified

Hepatic failure, unspecified without coma

Hepatic failure, unspecified with coma

Oesophageal varices with bleeding

Oesophageal varices with bleeding in

diseases classified elsewhere

Ascites

Peritonitis

Liver transplant (one code ever is sufficient for diagnosis)

Liver transplant status

V42.7

Liver transplant status

Complications of liver transplant

Z94.4

T86.4

Liver transplant rejection

T86.41

Liver transplant failure

$\mathrm{T} 86.42$

T86.43

Liver transplant infection
K72.1

K72.10

$\mathrm{K} 72.11$

K72.9

K72.90

K72.91

185

198.3

R18

K65
F61, F62, F63, F64, F65, F66, F67, F681, F688, F69, F7, F8, F90, F91, F92, F931, F932, F933, F938, F939, F94, F95, F96, F97, F98

F10-F14, F16, F18, F19

auses the ICD codes found in HSPRN multimorbidity SAS macro

\section{Additional file}

Additional file 1 Figure S1 HCV+ group exclusion flowchart. (DOCX 25 kb)

\section{Acknowledgements}

Parts of this material are based on data and information compiled and provided by Canadian Institute for Health Information (CIHI). However, the analyses, conclusions, opinions, and statements expressed herein are those of the author, and not necessarily those of $\mathrm{CIHI}$. Parts of this material are based on data and information provided by Cancer Care Ontario (CCO). The opinions, results, view, and conclusions reported in this paper are those of the authors and do not necessarily reflect those of CCO. No endorsement by CCO is intended or should be inferred.

The authors would like to thank Michael Fitzgerald and David Mackie for their help editing the manuscript. 


\section{Authors' contributions}

CLC, CG, JD, JK, RB, LB and CEK made substantial contributions to the conception and design of the study. CLC, CG, JD, and CEK were responsible for data acquisition and analysis. CLC, CG, JD, JK, RB, LB and CEK were responsible for interpretation of the data. CLC and CEK drafted the initial version of this manuscript. CLC, CG, JD, JK, RB, LB and CEK provided feedback. CLC, CG, JD, JK, RB, LB and CEK approved the submitted version and agree to both to be personally accountable for the author's own contributions and to ensure that questions related to the accuracy or integrity of any part of the work, even ones in which the author was not personally involved, are appropriately investigated, resolved, and the resolution documented in the literature. All authors read and approved the final manuscript.

\section{Funding}

This study was supported by ICES, which is funded by an annual grant from the Ontario Ministry of Health and Long-Term Care (MOHLTC). The opinions, results and conclusions reported in this paper are those of the authors and are independent from the funding sources. No endorsement by ICES or the Ontario MOHLTC is intended or should be inferred.

This study was supported by ICES, which is funded by an annual grant from the Ontario Ministry of Health and Long-Term Care (MOHLTC). The opinions, results and conclusions reported in this article are those of the authors and are independent from the funding sources. No endorsement by ICES or the Ontario MOHLTC is intended or should be inferred.

None of the funding bodies were involved in designing the study, data collection, analysis, interpretation of data, or writing the manuscript.

\section{Availability of data and materials}

The dataset from this study is held securely in coded form at ICES. While data sharing agreements prohibit ICES from making the dataset publicly available, access may be granted to those who meet pre-specified criteria for confidential access, available at www.ices.on.ca/DAS. The full dataset creation plan and underlying analytic code are available from the authors upon request, understanding that the computer programs may rely upon coding templates or macros that are unique to ICES and are therefore either inaccessible or may require modification.

\section{Ethics approval and consent to participate}

This study was approved by the institutional review board at Sunnybrook Health Sciences Centre, Toronto, Canada, and the Ottawa Health Sciences Network Research Ethics Board (OHSN-REB \#20120566$01 \mathrm{H}$ ), which allowed for administrative permission from the TOHVHP to access the raw data. No additional administrative permission was required to access ICES data, which links data using unique encoded identifiers and data are analysed at ICES.

\section{Consent for publication}

The manuscript does not contain any individual participant's data.

\section{Competing interests}

The authors declare that they have no competing interests.

\section{Author details}

${ }^{1}$ Department of Medicine, University of Ottawa, Ottawa, Canada. ${ }^{2}$ Clinical Epidemiology Program, Ottawa Hospital Research Institute, The Ottawa Hospital-General Campus, G12-501 Smyth Rd, Ottawa, Ontario K1H8L6, Canada. ${ }^{3}$ CES, Toronto, Canada. ${ }^{4}$ Department of Family and Community Medicine, University of Toronto, Toronto, Canada. ${ }^{5}$ Dalla Lana School of Public Health, University of Toronto, Toronto, Ontario, Canada. ${ }^{6}$ Sandy Hill Community Health Centre, Ottawa, Canada. ${ }^{7}$ Bruyère Research Institute, Ottawa, Canada. ${ }^{8}$ School of Epidemiology and Public Health, University of Ottawa, Ottawa, Canada. ${ }^{9}$ Department of Family Medicine, University of Ottawa, Ottawa, Canada.
Received: 1 May 2019 Accepted: 24 July 2019

Published online: 23 August 2019

\section{References}

1. Rotermann M, Langlois K, Andonov A, Trubnikov M. Seroprevalence of hepatitis B and C virus infections: results from the 2007 to 2009 and 2009 to 2011 Canadian health measures survey. Health Rep. 2013;24(11):3-13.

2. Payne $E$, Totten $S$, Archibald C. Hepatitis C surveillance in Canada. Can Commun Dis Rep. 2014;40(19):421-8.

3. Kwong JC, Ratnasingham S, Campitelli MA, et al. The impact of infection on population health: results of the Ontario burden of infectious diseases study. PLoS One. 2012;7(9):e44103.

4. Myers RP, Krajden M, Bilodeau M, et al. Burden of disease and cost of chronic hepatitis C infection in Canada. Can J Gastroenterol Hepatol. 2014; 28(5):243-50.

5. Fabrizi F, Donato FM, Messa P. Association between hepatitis $C$ virus and chronic kidney disease: a systematic review and meta-analysis. Ann Hepatol. 2018;17(3):364-91.

6. Henson JB, Sise ME. The association of hepatitis $C$ infection with the onset of CKD and progression into ESRD. Semin Dial. 2019;32(2):108-18

7. Kuna L, Jakab J, Smolic R, Wu GY, Smolic M. HCV extrahepatic manifestations. J Clin Transl Hepatol. 2019:7(2):172-82.

8. Park H, Chen C, Wang W, Henry L, Cook RL, Nelson DR. Chronic hepatitis $\mathrm{C}$ virus (HCV) increases the risk of chronic kidney disease (CKD) while effective HCV treatment decreases the incidence of CKD. Hepatology. 2018;67(2):492-504

9. Pol S, Parlati L, Jadoul M. Hepatitis C virus and the kidney. Nat Rev Nephrol. 2019;15(2):73-86.

10. Tsui Jl, Vittinghoff E, Shlipak MG, et al. Association of hepatitis $C$ seropositivity with increased risk for developing end-stage renal disease. Arch Intern Med. 2007;167(12):1271-6.

11. Adinolfi LE, Nevola R, Rinaldi L, Romano C, Giordano M. Chronic hepatitis C virus infection and depression. Clin Liver Dis. 2017;21(3):517-34.

12. Negro F, Esmat G. Extrahepatic manifestations in hepatitis $C$ virus infection. J Adv Res. 2017:8(2):85-7.

13. Yeoh SW, Holmes ACN, Saling MM, Everall IP, Nicoll AJ. Depression, fatigue and neurocognitive deficits in chronic hepatitis C. Hepatol Int. 2018;12(4): 294-304.

14. Adinolfi $L E$, Nevola R, Lus G, et al. Chronic hepatitis C virus infection and neurological and psychiatric disorders: an overview. World J Gastroenterol. 2015;21(8):2269-80.

15. Pol S, Vallet-Pichard A, Hermine O. Extrahepatic cancers and chronic HCV infection. Nat Rev Gastroenterol Hepatol. 2018;15(5):283-90.

16. Masarone M, Persico M. Hepatitis C virus infection and non-hepatocellular malignancies in the DAA era: a systematic review and meta-analysis. Liver Int. 2019;39(7):1292-306.

17. Negro F. Facts and fictions of HCV and comorbidities: steatosis, diabetes mellitus, and cardiovascular diseases. J Hepatol. 2014;61 (1 Suppl):S69-78.

18. Gastaldi G, Goossens N, Clement S, Negro F. Current level of evidence on causal association between hepatitis $\mathrm{C}$ virus and type 2 diabetes: a review. J Adv Res. 2017;8(2):149-59.

19. Fabiani S, Fallahi P, Ferrari SM, Miccoli M, Antonelli A. Hepatitis C virus infection and development of type 2 diabetes mellitus: systematic review and meta-analysis of the literature. Rev Endocr Metab Disord. 2018;19(4):405-20.

20. Negro F, Forton D, Craxi A, Sulkowski MS, Feld JJ, Manns MP. Extrahepatic morbidity and mortality of chronic hepatitis C. Gastroenterology. 2015; 149(6):1345-60

21. Petta S. Hepatitis C virus and cardiovascular: A review. J Adv Res. 2017; 8(2):161-8.

22. Petta S, Macaluso FS, Craxi A. Cardiovascular diseases and HCV infection: a simple association or more? Gut. 2014;63(3):369-75.

23. Dore GJ, Altice F, Litwin AH, et al. Elbasvir-Grazoprevir to treat hepatitis $\mathrm{C}$ virus infection in persons receiving opioid agonist therapy: a randomized trial. Ann Intern Med. 2016;165(9):625-34.

24. Klein MB, Rollet KC, Saeed S, et al. HIV and hepatitis C virus coinfection in Canada: challenges and opportunities for reducing preventable morbidity and mortality. HIV Med. 2013;14(1):10-20.

25. Stasi C, Silvestri C, Berni R, et al. Epidemiological, demographic and clinical data on chronic viral hepatitis C in Tuscany. Curr Med Res Opin. 2019;35(4):661-6. 
26. Sicras-Mainar A, Navarro-Artieda R, Saez-Zafra M. Comorbidity, concomitan medication, use of resources and healthcare costs associated with chronic hepatitis C virus carriers in Spain. Gastroenterol Hepatol. 2018;41(4):234-44.

27. Lauffenburger JC, Mayer CL, Hawke RL, Brouwer KL, Fried MW, Farley JF. Medication use and medical comorbidity in patients with chronic hepatitis C from a US commercial claims database: high utilization of drugs with interaction potential. Eur J Gastroenterol Hepatol. 2014;26(10):1073-82.

28. Liu CH, Yu ML, Peng CY, et al. Comorbidities, concomitant medications and potential drug-drug interactions with interferon-free direct-acting antiviral agents in hepatitis C patients in Taiwan. Aliment Pharmacol Ther. 2018; 48(11-12):1290-300.

29. Ruzicka DJ, Tetsuka J, Fujimoto G, Kanto T. Comorbidities and comedications in populations with and without chronic hepatitis $C$ virus infection in Japan between 2015 and 2016. BMC Infect Dis. 2018;18(1):237.

30. Louie KS, St Laurent S, Forssen UM, Mundy LM, Pimenta JM. The high comorbidity burden of the hepatitis $C$ virus infected population in the United States. BMC Infect Dis. 2012;12:86.

31. Bacon BR, Gordon SC, Lawitz E, et al. Boceprevir for previously treated chronic HCV genotype 1 infection. N Engl J Med. 2011;364(13):1207-17.

32. Myers RP, Ramji A, Bilodeau M, Wong S, Feld JJ. An update on the management of hepatitis $C$ : consensus guidelines from the Canadian association for the study of the liver. Can J Gastroenterol. 2012;26(6):359-75.

33. Feld JJ, Jacobson IM, Hezode C, et al. Sofosbuvir and Velpatasvir for HCV genotype 1, 2, 4, 5, and 6 infection. N Engl J Med. 2015;373(27):2599-607.

34. Sulkowski M, Hezode C, Gerstoft J, et al. Efficacy and safety of 8 weeks versus 12 weeks of treatment with grazoprevir (MK-5172) and elbasvir (MK8742) with or without ribavirin in patients with hepatitis $C$ virus genotype 1 mono-infection and HIV/hepatitis C virus co-infection (C-WORTHY): a randomised, open-label phase 2 trial. Lancet. 2015;385(9973):1087-97.

35. Bourliere M, Gordon SC, Flamm SL, et al. Sofosbuvir, Velpatasvir, and Voxilaprevir for previously treated HCV infection. N Engl J Med. 2017; 376(22):2134-46

36. Poordad F, Felizarta F, Asatryan A, et al. Glecaprevir and pibrentasvir for 12 weeks for hepatitis $C$ virus genotype 1 infection and prior direct-acting antiviral treatment. Hepatology. 2017;66(2):389-97.

37. Nagaty A, Abd El-Wahab EW. Real-life results of sofosbuvir based therapy in chronic hepatitis C -naive and -experienced patients in Egypt. PLoS One. 2017;12(10):e0184654.

38. Miotto N, Mendes LC, Zanaga LP, et al. All-oral direct antiviral treatment for hepatitis $C$ chronic infection in a real-life cohort: the role of cirrhosis and comorbidities in treatment response. PLoS One. 2018;13(7):e0199941.

39. Austin PC, Daly PA, Tu JV. A multicenter study of the coding accuracy of hospital discharge administrative data for patients admitted to cardiac care units in Ontario. Am Heart J. 2002;144(2):290-6.

40. Gershon AS, Wang C, Guan J, Vasilevska-Ristovska J, Cicutto L, To T. Identifying patients with physician-diagnosed asthma in health administrative databases. Can Respir J. 2009;16(6):183-8.

41. Schultz SE, Rothwell DM, Chen Z, Tu K. Identifying cases of congestive heart failure from administrative data: a validation study using primary care patient records. Chronic Dis Inj Can. 2013;33(3):160-6.

42. Gershon AS, Wang C, Guan J, Vasilevska-Ristovska J, Cicutto L, To T. Identifying individuals with physcian diagnosed COPD in health administrative databases. COPD. 2009;6(5):388-94.

43. Jaakkimainen RL, Bronskill SE, Tierney MC, et al. Identification of physiciandiagnosed Alzheimer's disease and related dementias in population-based administrative data: a validation study using family physicians' electronic medical records. J Alzheimers Dis. 2016;54(1):337-49.

44. Hux JE, Ivis F, Flintoft V, Bica A. Diabetes in Ontario: determination of prevalence and incidence using a validated administrative data algorithm. Diabetes Care. 2002;25(3):512-6.

45. Tu K, Campbell NR, Chen ZL, Cauch-Dudek KJ, McAlister FA. Accuracy of administrative databases in identifying patients with hypertension. Open Med. 2007;1(1):e18-26.

46. Antoniou T, Zagorski B, Loutfy MR, Strike C, Glazier RH. Validation of case-finding algorithms derived from administrative data for identifying adults living with human immunodeficiency virus infection. PLoS One. 2011;6(6):e21748.

47. Widdifield J, Bernatsky S, Paterson JM, et al. Accuracy of Canadian health administrative databases in identifying patients with rheumatoid arthritis: a validation study using the medical records of rheumatologists. Arthritis Care Res. 2013;65(10):1582-91.
48. Mondor L, Maxwell CJ, Bronskill SE, Gruneir A, Wodchis WP. The relative impact of chronic conditions and multimorbidity on health-related quality of life in Ontario long-stay home care clients. Qual Life Res. 2016;25(10): 2619-32.

49. Thavorn K, Maxwell CJ, Gruneir A, et al. Effect of socio-demographic factors on the association between multimorbidity and healthcare costs: a population-based, retrospective cohort study. BMJ Open. 2017;7(10): e017264.

50. Pefoyo AJ, Bronskill SE, Gruneir A, et al. The increasing burden and complexity of multimorbidity. BMC Public Health. 2015;15:415.

51. Gruneir A, Bronskill SE, Maxwell CJ, et al. The association between multimorbidity and hospitalization is modified by individual demographics and physician continuity of care: a retrospective cohort study. BMC Health Serv Res. 2016;16:154.

52. Lane NE, Maxwell CJ, Gruneir A, Bronskill SE, Wodchis WP. Absence of a socioeconomic gradient in older adults' survival with multiple chronic conditions. EBioMedicine. 2015;2(12):2094-100.

53. Petrosyan $Y$, Bai $Y Q$, Kone Pefoyo AJ, et al. The relationship between diabetes care quality and diabetes-related hospitalizations and the modifying role of comorbidity. Can J Diabetes. 2017;41(1):17-25.

54. Mondor L, Maxwell CJ, Hogan DB, et al. Multimorbidity and healthcare utilization among home care clients with dementia in Ontario, Canada: a retrospective analysis of a population-based cohort. PLoS Med. 2017;14(3): e1002249.

55. Huntley AL, Johnson R, Purdy S, Valderas JM, Salisbury C. Measures of multimorbidity and morbidity burden for use in primary care and community settings: a systematic review and guide. Ann Fam Med. 2012; 10(2):134-41.

56. Gower E, Estes C, Blach S, Razavi-Shearer K, Razavi H. Global epidemiology and genotype distribution of the hepatitis C virus infection. J Hepatol. 2014; 61(1 Suppl):\$45-57.

57. Polaris Observatory HCVC. Global prevalence and genotype distribution of hepatitis C virus infection in 2015: a modelling study. Lancet Gastroenterol Hepatol. 2017;2(3):161-76.

58. Breslow NE, Day NE. Statistical methods in cancer research. Volume II--The design and analysis of cohort studies. IARC Sci Publ. 1987:82:1-406.

59. Grebely J, Haire B, Taylor LE, et al. Excluding people who use drugs or alcohol from access to hepatitis $C$ treatments - is this fair, given the available data? J Hepatol. 2015;63(4):779-82.

60. WHO. Global hepatitis report 2017. Geneva: World Health Organization, 2017.

61. Russo MW, Fried MW. Side effects of therapy for chronic hepatitis C. Gastroenterology. 2003;124(6):1711-9.

62. Shah $\mathrm{H}$, Bilodeau M, Burak KW, et al. The management of chronic hepatitis C: 2018 guideline update from the Canadian association for the study of the liver. CMAJ. 2018;190(22):E677-E87.

63. Socias ME, Ti L, Wood E, et al. Disparities in uptake of direct-acting antiviral therapy for hepatitis $C$ among people who inject drugs in a Canadian setting. Liver Int. 2019;39(8):1400-7. https://doi.org/10.1111/liv.14043.

64. Boucher LM, Bayoumi AM, Mark AE, et al. Hepatitis $C$ testing, status and treatment among marginalized people who use drugs in an Inner city setting: an observational cohort study. Subst Use Misuse. 2019;54(1):18-30.

65. Marshall AD, Saeed S, Barrett $L$, et al. Restrictions for reimbursement of direct-acting antiviral treatment for hepatitis $C$ virus infection in Canada: a descriptive study. CMAJ Open. 2016;4(4):E605-E14.

66. Martin NK, Vickerman $P$, Grebely J, et al. Hepatitis $C$ virus treatment for prevention among people who inject drugs: modeling treatment scale-up in the age of direct-acting antivirals. Hepatology. 2013;58(5):1598-609.

67. Backus LI, Boothroyd DB, Phillips BR, Belperio P, Halloran J, Mole LA. A sustained virologic response reduces risk of all-cause mortality in patients with hepatitis C. Clin Gastroenterol Hepatol. 2011;9(6):509-16 e1.

68. Cacoub P, Bondin M, Hayes O, Pinsky B, Negro F. Quality of life in patients with psychiatric disorders: pooled analysis from Glecaprevir/Pibrentasvir Registrational studies. (abstract \#150). In: The liver meeting. San Francisco: AASLD; 2018.

69. Hsu YC, Ho HJ, Huang YT, et al. Association between antiviral treatment and extrahepatic outcomes in patients with hepatitis C virus infection. Gut. 2015; 64(3):495-503.

70. Janjua N, Wong S, Rossi C, et al. The impact of HCV sustained virologic response from direct acting antiviral and interferon-based treatments on mortality in a large population based cohort study (abstract \#145). In: The liver meeting. San Francisco: AASLD; 2018. 
71. Park H, Wang W, Henry L, Nelson D. Impact of all-Oral direct-acting antivirals on clinical and economic outcomes in chronic hepatitis C virus-infected patients in the U.S. (abstract \#146). In: The liver meeting. San Francisco: AASLD; 2018.

72. Rossi C, Butt Z, Chapinal N, et al. Sustained virologic responses reduces the incidence of extrahepatic manifestations in chronic hepatitis $\mathrm{C}$ infection. (abstract \#148). In: The liver meeting. San Francisco: AASLD; 2018.

73. van der Meer AJ, Veldt BJ, Feld JJ, et al. Association between sustained virological response and all-cause mortality among patients with chronic hepatitis C and advanced hepatic fibrosis. JAMA. 2012;308(24):2584-93.

74. Dahrouge S, Devlin R, Hogg B, Russell G, Coyle D, Fergusson D. The economic impact of improvements in primary healthcare performance. Ottawa, ON: Canadian Health Services Research Foundation. 2012.

75. Rothman AA, Wagner EH. Chronic illness management: what is the role of primary care? Ann Intern Med. 2003;138(3):256-61.

76. Mitruka K, Thornton K, Cusick S, et al. Expanding primary care capacity to treat hepatitis $C$ virus infection through an evidence-based care model--Arizona and Utah, 2012-2014. MMWR Morb Mortal Wkly Rep. 2014;63(18):393-8.

77. GroessI EJ, Weingart KR, Gifford AL, Asch SM, Ho SB. Development of the hepatitis C self-management program. Patient Educ Couns. 2011; 83(2):252-5.

78. Gonzalez SA, Fierer DS, Talal AH. Medical and behavioral approaches to engage people who inject drugs into Care for Hepatitis C Virus Infection. Addict Disord Their Treat. 2017;16(2 Suppl 1):S1-S23.

79. Meyer JP, Moghimi Y, Marcus R, Lim JK, Litwin AH, Altice FL. Evidence-based interventions to enhance assessment, treatment, and adherence in the chronic hepatitis C care continuum. Int J Drug Policy. 2015;26(10):922-35.

80. Talal AH, Thomas DL, Reynolds JL, Khalsa JH. Toward optimal control of hepatitis $C$ virus infection in persons with substance use disorders. Ann Intern Med. 2017;166(12):897-8.

\section{Publisher's Note}

Springer Nature remains neutral with regard to jurisdictional claims in published maps and institutional affiliations.

Ready to submit your research? Choose BMC and benefit from:

- fast, convenient online submission

- thorough peer review by experienced researchers in your field

- rapid publication on acceptance

- support for research data, including large and complex data types

- gold Open Access which fosters wider collaboration and increased citations

- maximum visibility for your research: over $100 \mathrm{M}$ website views per year

At $\mathrm{BMC}$, research is always in progress.

Learn more biomedcentral.com/submissions 